\title{
IMMUNOHISTOCHEMICAL ASSESSMENT OF E-CADHERIN AND $\beta$-CATENIN IN TRICHOFOLLICULOMAS AND TRICHOEPITHELIOMAS
}

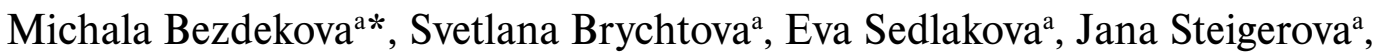 \\ Alice Hlobilkova ${ }^{\mathrm{a}}$, Martina Bienova ${ }^{\mathrm{b}}$, Renata Kucerova ${ }^{\mathrm{b}}$, Tomas Brychta ${ }^{\mathrm{c}}$, Veronika Krejci ${ }^{\mathrm{a}}$, \\ Zdenek Kolar ${ }^{\mathrm{a}}$
}

\author{
a Laboratory of Molecular Pathology and Department of Pathology, Faculty of Medicine and Dentistry, Palacky University, \\ Hnevotinska 3, 77515 Olomouc, Czech Republic \\ ${ }^{b}$ Department of Dermatovenerology, Faculty of Medicine and Dentistry, Palacky University and University Hospital, I. P. Pav- \\ lova 6, 77520 Olomouc, Czech Republic \\ c Department of Internal Medicine, SPEA Olomouc, nam. Hrdinu 2, 77200 Olomouc, Czech Republic \\ e-mail:mfiuraskova@seznam.cz
}

Received: September 5, 2007; Accepted: November 1, 2007

Key words: E-cadherin/ $\beta$-catenin/Immunohistochemistry/Pathogenesis/Trichoepithelioma/Trichofolliculoma

Background: Trichofolliculomas and trichoepitheliomas are benign skin neoplasms originating from hair follicle cells. They result from defects in the signaling pathways that regulate hair follicle morphogenesis and regeneration. Thus they seem to be an excellent model of these processes. It is known that the E-cadherin/ $\beta$-catenin system of adhesion molecules plays a crucial role in the maintenance of tissue architecture.

Aim: The aim of the present study was to investigate their involvement in benign hair follicle tumor development.

Methods: Semiquantitative intensity of expression were examined in formalin-fixed and paraffin-embedded tissue sections of 53 trichoepitheliomas, 15 trichofolliculomas and 19 normal skin samples by indirect immunohistochemistry.

Results: The intensity of E-cadherin/ $\beta$-catenin expression in tumor cells did not differ from controls. However, normal hair follicles cells exhibited membranous E-cadherin/ $\beta$-catenin expression, whereas both types of tumors, particularly trichoepitheliomas, showed E-cadherin/ $\beta$-catenin expression with a predominantly cytoplasmic localization.

Conclusions:We suggest that this dystopic distribution of the E-cadherin/ $\beta$-catenin complex in hair follicle tumor cells may be a marker of cell-cell adhesion disruption which may contribute to the tumor formation.

\section{INTRODUCTION}

Trichofolliculomas (TF) and trichoepitheliomas (TE) are benign tumors derived from the hair follicle (hair follicle tumors, HFT) ( ref. $^{1}$ ). According to recent data, disruption of normal dermal-epidermal interactions in HFT resulting in altered hair follicle cell morphogenesis is assumed ${ }^{2}$.

In normal epithelial structures, cell-cell junctions play an important role in the maintenance, integrity and morphology of the epithelium ${ }^{3}$. It has been reported that the E-cadherin/ $\beta$-catenin system of adhesion molecules plays a crucial role in this processes ${ }^{4}$. E-cadherin is a cell adhesion transmembrane molecule which is a member of a family of functionally related transmembrane glycoproteins that mediate $\mathrm{Ca}^{2+}$-dependent intercellular cellular adhesion $^{5}$. E-cadherin is important for epidermal intercellular adherence because it is required for the adhesive properties of keratinocytes and skin differentiation and loss of E-cadherin-mediated cell adhesion is one rate-limiting step in the progression from adenoma to carcinoma ${ }^{6}$. Furthermore, it determines the morphogenesis and hair follicle cycling ${ }^{7}$. The adhesion is mediated via interaction with adjacent cells through their N-terminal ectodomains and the cytoplasmic terminal tail of E-cadherin links specifically to $\beta$-catenin that binds directly to the cytoskeletal actin $^{5}$. A deficiency in E-cadherin causes loss of adherent junctions which leads to impaired intercellular signaling, but not to direct tumor transformation ${ }^{8}$. It has been reported that dysfunction or disruption of cell adhesion molecules accompany the invasiveness and metastatic behavior of malignant cells ${ }^{9}$ and that a loss or decreased expression of E-cadherin is frequently observed mainly in advanced, poorly differentiated carcinomas ${ }^{10}$.

$\beta$-Catenin is a molecular sensor that integrates cellcell junctions and cytoskeletal dynamics with signaling pathways affecting morphogenesis, tissue homeostasis, and intercellular communication within tissues ${ }^{11}$. It has been shown that differentiation of the hair follicle is regulated and linked to the same pathways that initiate its development ${ }^{12}$. Generally, $\beta$-catenin has a dual function. It plays a key role in cell-cell adhesion by linking cadherins to $\alpha$-catenin and cytoskeletal actin ${ }^{4}$. In the absence of Wnt signal, $\beta$-catenin is constitutively down-regulated by a multicomponent destruction complex containing GSK3 $\beta$ (glycogen synthase kinase $3 \beta$ ), axin 
and a tumor suppressor APC (adenomatous polyposis coli). These proteins promote the phosphorylation of serine and threonine residues in the $\mathrm{NH}_{2}$-terminal region of $\beta$-catenin. $\beta$-Catenin is then degraded by casein kinase CK1 and protein phosphatases PP2A and PP2C through the ubiquitin proteasome pathway. Wnt signaling inhibits this process, leading to an accumulation of $\beta$-catenin in the nucleus which promotes the formation of transcriptionally active complexes with members of the Tcf/lef family (T-cell factor/lymphoid enhancer factor). The Tcf/ $\beta$-catenin heterodimers act as bipartite transcription factors and activate expression of the specific Wnt responsive genes that encode proteins regulating cell cycle, e.g. c-Myc, Cyclin D1 and Pitx $2^{13-15}$. Alterations in $\beta$-catenin mediated regulation have been demonstrated mainly during cancer development, where mutations of the $\beta$-catenin gene $C T N N B .1$ result in disruption of a large number of cellular functions leading to loss of growth control and neoplastic change ${ }^{16-19}$. However, $\beta$-catenin mutations also induce benign tumor growth, as has been demonstrated for example in pilomatricomas ${ }^{7}$.

This study is focused on study of the E-cadherin/ $\beta$-catenin expression in trichofolliculomas (TF) and trichoepitheliomas (TE), benign adnexal neoplasms originating from the hair follicle ${ }^{20,21}$. We hypothesize that aberrant activation of these cell adhesion molecules may be implicated in hair follicle tumor development and can contribute to better understanding of hair follicle cell regulation.

\section{MATERIAL AND METHODS}

\section{Samples}

Formalin-fixed, paraffin-embedded, routine biopsy specimens were taken from the tissue archive of Department of Pathology, Faculty of Medicine and Dentistry, Palacký University, Olomouc. Each sample was reexamined by an experienced pathologist in order to confirm the diagnosis. Fifty-three trichoepitheliomas and fifteen trichofolliculomas were analyzed. Nineteen specimens of healthy scalp skin taken from authopsy ( 9 samples) and from biopsy (10 samples) were used as controls.

\section{Immunohistochemistry}

Indirect immnunohistochemical staining of $5 \mu \mathrm{m}$ thick tissue sections was performed using the immunostainer Benchmark (Ventana Medical Systems S.A.). Sections were incubated with mouse monoclonal antibodies anti-E-cadherin (clone 36B5, dilution $1: 25$, Novocastra, UK), anti- $\beta$-catenin (clone E-5, dilution 1 : 50, Santa Cruz Biotechnology, CA, USA). Colon carcinoma and ductal breast carcinoma tissues were used as a positive control for $\beta$-catenin and E-cadherin, respectively. The primary antibodies were omitted in the case of negative controls. Semiquantitative assessment of protein expression was performed using a modified $\mathrm{H}$-score in which both intensity and proportion of staining was categorized. Category A indicated the proportion of positive cell stain- ing throughout the section and was assigned a scale from 0 to $3(0=0-4 \% ; 1=5-24 \% ; 2=25-49 \% ; 3=50-100 \%)$. Category B represented the average intensity; the presence of negative, weak, intermediate and strong staining was given a score from 0 to 3 . Category $\mathrm{A}$ was multiplied by category B to form a multiplicative score. The cases were sorted into three subgroups; H-score 0 referred to negative expression; H-score 1-2 to weak expression; H-score 3-9 to moderate/strong expression.

\section{Statistical analysis}

The protein expressions were evaluated using a Chi-square test $(p<0.05)$. The cellular localizations of proteins were statistically analyzed using Fisher's exact test with Yates correction $(\mathrm{p}<0.05)$.

\section{RESULTS}

\section{E-cadherin}

E-cadherin positivity was found in the membranes of epidermal keratinocytes and normal hair follicle cells and sebaceous cells (Fig. 1a) where moderate to strong intensity of the protein expression prevailed (Fig. 2a). When comparing normal epithelial/hair follicle/sebaceous cells to tumorous ones, marked differences in protein expression or localization were found. In TF, subcellular relocalization of the protein was observed (Fig. 1b); apart from typical membranous, also cytoplasmic (42.9\%) or both cytoplasmic and membranous localization of protein $(21.4 \%)$ were seen $(p=0.003)$ (Fig. $2 b)$. The intensity of E-cadherin expression in tumor cells did not differ from control cells.

TE exhibited total loss of purely membranous E-cadherin localization; both cytoplasmic (68.4\%) and combined membranous and cytoplasmic (28.9\%) expression was observed ( $p=0.0001)$ (Fig. 2b). The protein expression in tumor cells was significantly decreased in comparison to normal control keratinocytes $(p=0.01)$. Furthermore, TE exprimed E-cadherin in lower levels than TF $(p=0.05)$.

\section{$\beta$-catenin}

The protein $\beta$-catenin was present in high to moderate levels in membranes of epidermal keratinocytes and in normal hair follicle cells (Fig. 3a, 4a). In TF, significant changes in protein localization were observed in contrast to control epithelial cells and cells of hair follicle and sebaceous glands $(p=0.001) ; 50 \%$ of the tumor samples had cytoplasmic only or combined membranous/cytoplasmic coexpression (Fig. 3b). TF showed similar intensities of $\beta$-catenin expression as control skin cells.

In TE, a significant loss of membrane-type expression was observed in contrast to control epithelium ( $p<0.0001$ ); $81.3 \%$ of tumor samples demonstrated cytoplasmic and $9.4 \%$ membranous/cytoplasmic $\beta$-catenin staining. The difference in $\beta$-catenin localization was apparent between TE and TF tumor cells $(p=0.002)$ whereas a membraneous pattern of staining prevailed in 
a

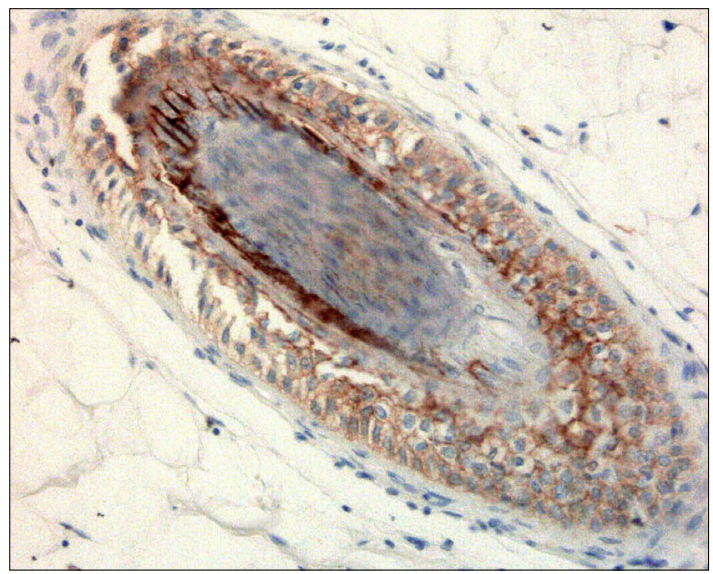

b

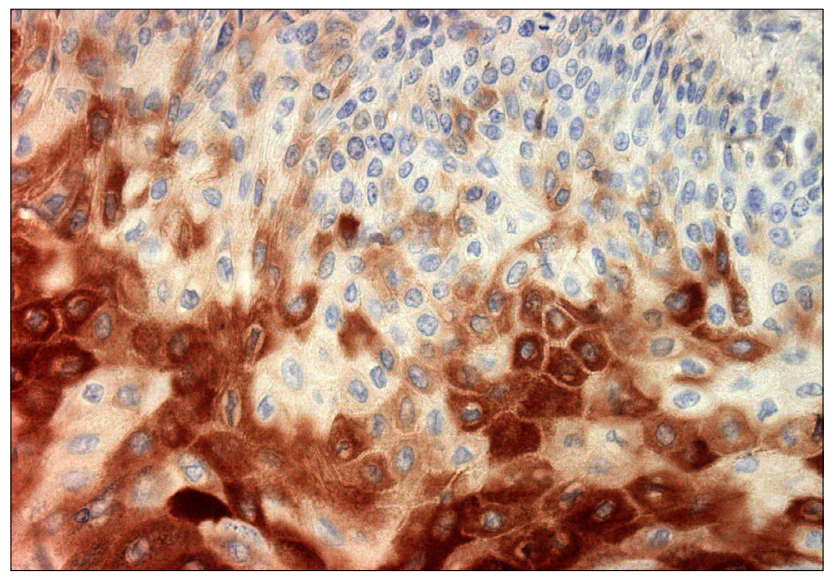

Fig. 1. Membranous staining of E-cadherin in the hair follicle of normal skin, original magnification $200 \times$ (a); Strong cytoplasmic staining of E-cadherin in benign trichofolliculoma cells, original magnification $400 \times$ (b).

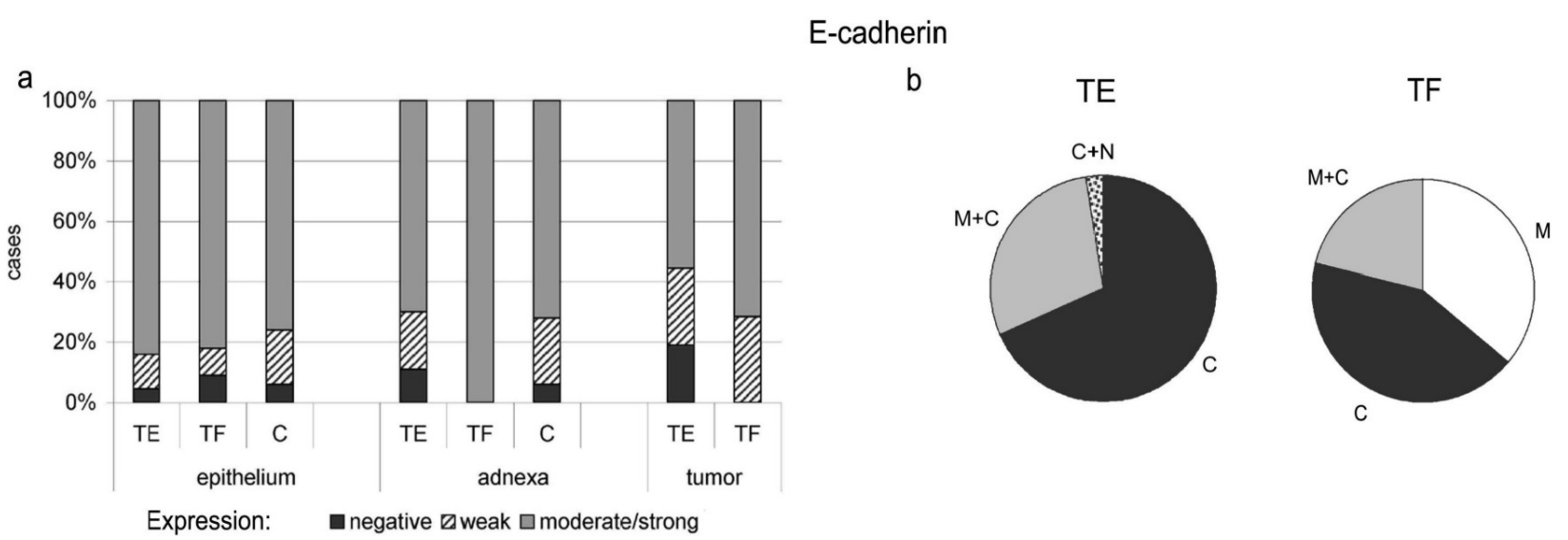

Fig. 2. Comparison of E-cadherin expression in the epithelium, adnexa and tumor of trichoepitheliomas (TE), trichofolliculomas (TF) and control skin (C) (a); E-cadherin distribution in the tumor samples (M=membranous, $\mathrm{C}=$ cytoplasmic, $\mathrm{N}=$ nuclear $)(\mathrm{b})$.

a

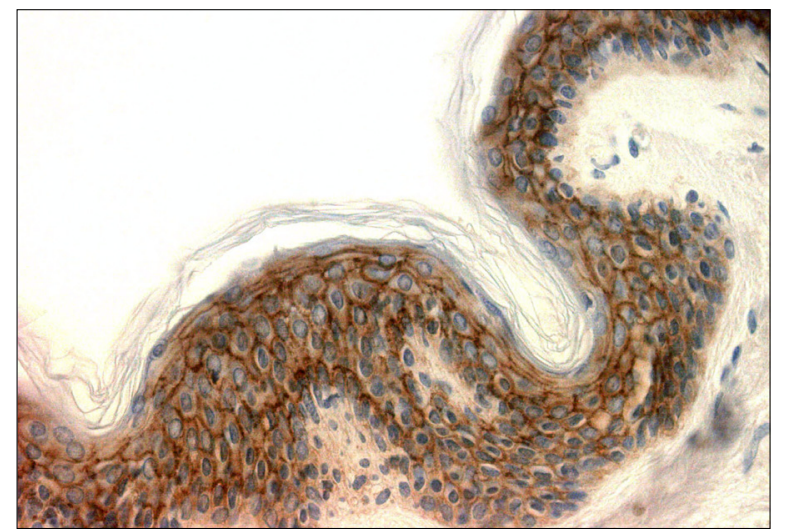

$\mathrm{b}$

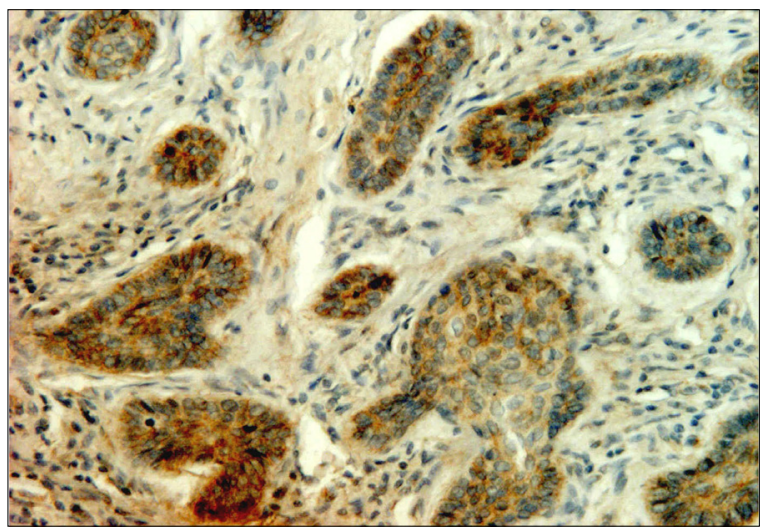

Fig. 3. Membranous staining of $\beta$-catenin in the control normal epidermis, original magnification $400 \times(a)$; $\beta$-catenin positivity on the membrane and in the cytoplasm of trichoepithelioma tumor cells, original magnification $320 \times(b)$. 


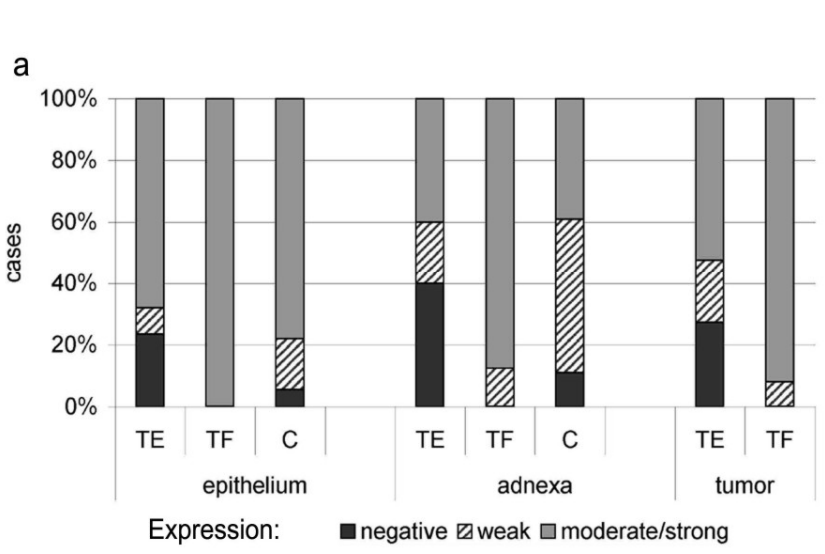

\section{$\beta$-catenin}

$\mathrm{b}$

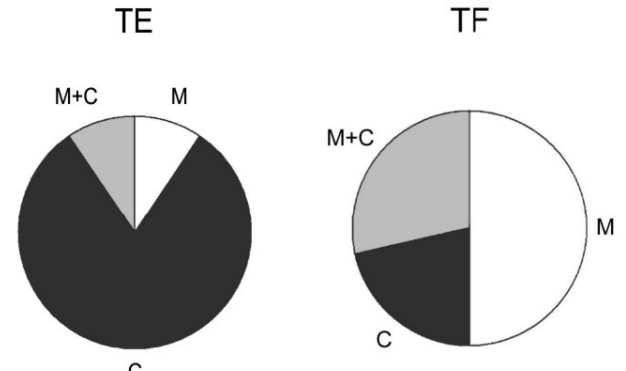

Fig. 4. Comparison of $\beta$-catenin expression in the epithelium, adnexa and tumor of trichoepitheliomas (TE), trichofolliculomas (TF) and control skin (C) (a); $\beta$-catenin localization in trichofolliculomas and trichoepitheliomas $(\mathrm{M}=$ membranous, $\mathrm{C}=$ cytoplasmic, $\mathrm{N}=$ nuclear $)(\mathrm{b})$.

TF (Fig. 4b). No nuclear $\beta$-catenin staining was found either in TE or TF. TE had only slightly reduced $\beta$-catenin expression compared to control cells. However, TE revealed a significant decrease in $\beta$-catenin in comparison to TF $(p=0.021)$.

\section{DISCUSSION}

In tumors, we revealed a loss of the membranous $\beta$-catenin immunostaining, which is usually observed in the normal keratinocytes, hair follicles cells and sebaceous cells, accompanied by translocation of the protein to the cytoplasmic compartment. Trichoepitheliomas exhibited mainly cytoplasmic, less frequently combined membranous/cytoplasmic staining. On the other hand a third of trichofolliculomas showed preserved membranous protein expression. Membranous localization of the protein is known to be associated with its physiological function as a modulator of intercellular communication, tissue morphogenesis and homeostasis in different cell types.

It has been proposed that $\beta$-catenin nuclear and/or cytoplasmic localization may correlate with $\beta$-catenin gene mutation ${ }^{22,23}$. In general, changes in $\beta$-catenin regulation have been demonstrated mainly during cancer development, where mutations of the $\beta$-catenin gene CTNNB.1 result in disruption of a number of its cellular functions leading to a loss of growth control. Recent studies have found that aberrant activation of $\beta$-catenin is also involved in the regulation of benign tumor growth. Exon 3 $\beta$-catenin-activating mutations were found in all cases of pilomatricoma; the tumors display both nuclear and cytoplasmic, but only focal membranous protein expression in the basaloid cells ${ }^{24,25}$. The nuclear protein accumulation has been demonstrated to be associated with its stabilization which is induced by inhibition of GSK3 $\beta$ and results in reduced $\beta$-catenin phosphorylation. However, in our study we demonstrated no nuclear $\beta$-catenin distribution. On this basis, we suggest that the Wnt signaling pathway is not involved in the trichofolliculoma and trichoepithelioma development. These data are paralleled by Demirkan et al. who detected no $\beta$-catenin gene mutation in other benign trichogenic tumors except of pilomatrixomas ${ }^{26}$. To support this hypothesis, c-myc and cyclin D1 expressions were analyzed in tumors (data not shown). The levels of c-myc and cyclin D did not differ from the protein expression in control hair follicle and sebaceous cells. Therefore, we consider cytoplasmic distribution of $\beta$-catenin to be important for the TE and TF formation.

Similarly, E-cadherin showed loss of membrane-type expression with relocalization into the cytoplasm of tumor cells, predominantly in trichoepitheliomas. No changes in intensity of expression however were found. While loss of E-cadherin expression has been observed in many malignancies as an indicator of the protein mutation associated with its enhanced transcriptional activity ${ }^{9}, 27-29$, the cytoplasmic or nuclear protein localization is considered to be a marker of alterations in its intercellular signaling. It has been reported that the decreased tyrosine phosphorylation of E-cadherin may reflect a loss of the E-cadherin/ $\beta$-catenin complex function and may be implicated in tumor invasion ${ }^{30}$.

When we compared TE and TF, a difference in protein localization was noted. In a large percentage of TF, membranous staining was preserved. This suggests that normal intercellular communication is, at least partly maintained. From a histogenetic point of view, trichofolliculomas are considered to be hamartomas of hair follicles whereas trichoepitheliomas demonstrate classical benign adnexal neoplasms, whose tumor cells, like in many other tumors, proliferate in the absence of stimulating normal signals ${ }^{31}$. We conclude that a disturbance in the normal cell-cell adherent junction is probably the key event in the trichofolliculoma and trichoepithelioma formation. 


\section{ACKNOWLEDGEMENTS}

This work was supported by the Ministry of Health of the Czech Republic (grant IGA MZ CR NR8386-3) and by the Ministry of Education of the Czech Republic (grant MSM 6198959216).

\section{REFERENCES}

1. Doglioni C, Piccinin S, Demontis S, Cangi MG, Pecciarini L, Chiarelli C, Armellin M, Vukosavljevic T, Boiocchi M, Maestro R. Alterations of beta-catenin pathway in non-melanoma skin tumors: loss of alpha-ABC nuclear reactivity correlates with the presence of beta-catenin gene mutation. Am J Pathol 2003; 163:2277-87.

2. Millar SE. Molecular mechanisms regulating hair follicle development. J Invest Dermatol 2002; 118:216-25.

3. Alami J, Williams BR, Yeger H. Differential expression of E-cadherin and beta-catenin in primary and metastatic Wilms's tumours. Mol Pathol 2003; 56:218-25.

4. Weis WI, Nelson WJ. Re-solving the cadherin-catenin-actin conundrum. J Biol Chem 2006; 281:35593-7.

5. Young $\mathrm{P}$, Boussadia $\mathrm{O}$, Halfter H, Grose R, Berger P, Leone DP, Robenek H, Charnay P, Kemler R, Suter U. E-cadherin controls adherent junctions in the epidermis and the renewal of hair follicles. EMBO J 2003; 22:5723-33.

6. Perl AK, Wilgenbus P, Dahl U, Semb H, Christofori G. A causal role for E-cadherin in the transition from adenoma to carcinoma. Nature 1998; 392:190-3.

7. Chan EF, Gat U, McNiff JM, Fuchs E. A common human skin tumour is caused by activating mutations in beta-catenin. Nat Genet 1999; 21:410-3.

8. Lu Z, Ghosh S, Wang Z, Hunter T. Downregulation of caveolin-1 function by EGF leads to the loss of E-cadherin, increased transcriptional activity of beta-catenin, and enhanced tumor cell invasion. Cancer Cell 2003; 4:499-515.

9. Campbell RJ, Pignatelli M. Molecular histology in the study of solid tumours. Mol Pathol 2002; 55:80-2.

10. Guilford P, Hopkins J, Harraway J, McLeod M, McLeod N, Harawira P, Taite H, Scoular R, Miller A, Reeve AE. E-cadherin germline mutations in familial gastric cancer. Nature 1998; 392:402-5.

11. Perez-Moreno M, Fuchs E. Catenins: keeping cells from getting their signals crossed. Dev Cell 2006; 11:601-12.

12. van Steensel MA, van Geel M, Steiljen PM The molecular basis of hair growth. Eur J Dermatol 2001; 11:348-52.

13. He TC, Sparks AB, Rago C, Hermeking H, Zawel L, da Costa LT, Morin PJ, Vogelstein B, Kinzler KW. Identification of c-MYC as a target of the APC pathway. Science 1998; 281:150-2.

14. Tetsu O, McCormick F. Beta-catenin regulates expression of cyclin D1 in colon carcinoma cells. Nature 1999; 398:422-6.

15. Briata P, Ilengo C, Corte G, Moroni C, Rosenfeld MG, Chen CY, Gherzi R. The Wnt/beta-catenin->Pitx2 pathway controls the turnover of Pitx2 and other unstable mRNAs. Mol Cell 2003; $12: 1201-11$.
16. Mirabelli-Primdahl L, Gryfe R, Kim H, Millar A, Luceri C, Dale D, Holowaty E, Bapat B, Gallinger S, Redston M. Beta-catenin mutations are specific for colorectal carcinomas with microsatellite instability but occur in endometrial carcinomas irrespective of mutator pathway. Cancer Res 1999; 59:3346-51.

17. Voeller HJ, Truica CI, Gelmann EP. Beta-catenin mutations in human prostate cancer. Cancer Res 1998; 58:2520-3.

18. Palacios J, Gamallo C. Mutations in the beta-catenin gene (CTNNB1) in endometrioid ovarian carcinomas. Cancer Res 1998; 58:1344-7.

19. Garcia-Rostan G, Tallini G, Herrero A, D'Aquila TG, Carcangiu ML, Rimm DL. Frequent mutation and nuclear localization of beta-catenin in anaplastic thyroid carcinoma. Cancer Res 1999; 59:1811-5.

20. Schulz T, Hartschuh W. The trichofolliculoma undergoes changes corresponding to the regressing normal hair follicle in its cycle. $\mathrm{J}$ Cutan Pathol 1998; 25:341-53.

21. Lum CA, Binder SW. Proliferative characterization of basal-cell carcinoma and trichoepithelioma in small biopsy specimens. J Cutan Pathol 2004; 31:550-4.

22. Hao X, Frayling IM, Willcocks TC, Han W, Tomlinson IP, Pignatelli MN, Pretlow TP, Talbot IC. Beta-catenin expression and allelic loss at APC in sporadic colorectal carcinogenesis. Virchows Arch 2002; 440:362-6.

23. Alami J, Williams BR, Yeger H. Differential expression of E-cadherin and beta-catenin in primary and metastatic Wilms's tumours. Mol Pathol 2003; 56:218-25.

24. Moreno-Bueno G, Gamallo C, Pérez-Gallego L, Contreras F, Palacios J. $\beta$ - catenin expression in pilomatrixomas. Relationship with $\beta$-catenin gene mutations and comparison with $\beta$-catenin expression in normal hair follicles. Brit. J Dermatol 2001; 145:57681.

25. Hassanein AM, Glanz SM. Beta-catenin expression in benign and malignant pilomatrix neoplasms. Br J Dermatol 2004; 150:5116.

26. Demirkan NC, Bir F, Erdem O, Düzcan E. Immunohistochemical expression of beta-catenin, E-cadherin, cyclin D1 and c-myc in benign trichogenic tumors. J Cutan Pathol 2007; 34:467-73.

27. Richmond PJ, Karayiannakis AJ, Nagafuchi A, Kaisary AV, Pignatelli M. Aberrant E-cadherin and alpha-catenin expression in prostate cancer: correlation with patient survival. Cancer Res 1997; 57:3189-93.

28. El-Bahrawy MA, Pignatelli M. E-cadherin and catenins: molecules with versatile roles in normal and neoplastic epithelial cell biology. Microsc Res Tech 1998; 43:224-32.

29. Kuroda N, Mizushima S, Guo L Jin Y, Tao L, Miyazaki E, Toi M, Naruse K, Hiroi M, Enzan H. Goblet cell carcinoid of the appendix: Investigation of the expression of beta-catenin and E-cadherin. Pathol Int 2001; 51:283-7.

30. Nawrocki B, Polette M, Van Hengel J, Tournier JM, Van Roy F, Birembault P. Cytoplasmic redistribution of E-cadherin-catenin adhesion complex is associated with down-regulated tyrosine phosphorylation of E-cadherin in human bronchopulmonary carcinomas. Am J Pathol 1998; 153:1521-30.

31. Tabs S, Avci O. Induction of the differentiation and apoptosis of tumor cells in vivo with efficiency and selectivity. Eur J Dermatol 2004; 14:96-102. 